\title{
Religião como linguagem: Uma filosofia da religião para a Ciência da Religião
}

\author{
André Luiz Alves da Silva*
}

\begin{abstract}
RESUMO
O presente artigo busca apresentar uma proposta de filosofia da religião que procure se apresentar não como filosofia religiosa, mas como uma filosofia que sendo tanto crítica quanto fundamento para o estudo do fenômeno religioso, se constitua como metateoria da Ciência da Religião. Para isso propõe-se a perspectiva da religião como linguagem. O itinerário problematiza as filosofias religiosas comprometidas com teologias específicas, passa pelo giro linguístico como um ganho conceitual da filosofia na discussão da linguagem que perpassa todo fenômeno cultural, inclusive a religião e a Ciência da Religião e finaliza propondo uma análise dos fenômenos religiosos a partir de seus jogos de linguagem, tendo como marco teórico principal a inflexão do giro linguístico pragmático de Ludwig Wittgenstein.
\end{abstract}

Palavras-chave: filosofia; religião; linguagem; jogos de linguagem.

\section{RELIGION AS LANGUAGE: A PHILOSOPHY OF RELIGION FOR THE SCIENCE OF RELIGION}

\begin{abstract}
This paper proposes a philosophy of religion which can present itself not as a religious philosophy, but as a philosophy both critical and foundational for the study of the religious phenomenon, constituting itself as a metatheory of the Science of Religion. For this task, a perspective of religion as a language is offered problematizing religious philosophies committed to specific theologies. The linguistic turn, as a conceptual
\end{abstract}

* Licenciatura em Filosofia, Especialização em Filosofia e Pensamento Político Contemporâneos pelo UNIFAI - Centro Universitário Assunção, São Paulo, SP), Mestrando em Ciências da Religião pela UMESP - Universidade Metodista de São Paulo. E-mail: andre@seo.adm.br. Lattes: http://lattes.cnpq.br/1190001951140073 
gain of philosophy in the discussion of language, permeates cultural phenomenon such as religion and Science of Religion. At the end, the paper proposes an analysis of religious phenomena from its language games, having as its main theoretical framework the inflection of Ludwig Wittgenstein's pragmatic linguistic turn.

Key words: Philosophy; Religion; Language; Language games.

"Deus" não é o nome de um ser para o qual a ciência tem ferramentas adequadas para descobrir"

\section{Introdução}

A Filosofia da Religião, como tal, é uma elaboração recente que data do século XVII, cuja obra inaugural é o texto de Immanuel Kant A religião nos limites da simples razão (1793). Desde então este ramo da filosofia passou a considerar a religião com especificidade em relação a outros objetos ou temas da filosofia tais como a estética, a lógica, o direito, entre outros. Apesar disto, as questões religiosas sempre estiveram presentes na reflexão filosófica já desde os pré-socráticos, inclusive enquanto objeto de crítica. Os filósofos da physis (gr.) que buscavam uma origem arché (gr.) material para o cosmos (gr.), além de não partirem necessariamente dos deuses também fizeram críticas a religiosidade grega, de certo modo vista como superstição, embora não negassem a existência de deuses. Sócrates foi condenado, embora talvez injustamente, pela acusação de apresentar outros deuses aos jovens. Platão desenvolveu sua Teoria das Ideias, grosso modo, separando mundo sensível e mundo inteligível, e com sua Teoria da Alma, produziu uma discussão, que embora intrinsecamente filosófica, se desdobrou-se em questões religiosas, tornando-se mais tarde, por exemplo, fundamentação para o cristianismo. Aristóteles inaugurou a teologia dentre as ciências teoréticas com o conceito de motor imóvel que dá origem a todos os outros movimentos e seres, retomado mais tarde como base da teologia de Tomás de Aquino. Sem contar que praticamente toda a filosofia medieval é uma discussão de base teológica e religiosa. Mas nem mesmo o alvorecer da filosofia moderna escapou de uma intensa discussão acerca de Deus e da religiosidade. Mesmo a

WILKINSON \& CAMPBELL, 2014, p. 286. 
filosofia contemporânea, que inaugura com o pensamento dos mestres da suspeita Marx, Nietzsche e Freud, surge como crítica à religião e à questão de Deus. Assim, apesar do nome "Filosofia da Religião" só surgir no período iluminista, a religião é um tema presente em toda a história do pensamento filosófico ocidental.

Todavia é importante notar a forma com que os temas da religião têm sido tratados pela filosofia ao longo destes mais de 2.500 anos de história do pensamento ocidental. Até o período da modernidade, mais especificamente até o século XIX, não é nítida a separação entre a religião e as demais áreas da sociedade humana como o direito, a política, as ciências etc. Em verdade, a religião era parte integrante e fundante da cultura. Todas essas áreas da sociedade a ela se subsumiam. A religião era o fundamento das sociedades pré-modernas. Semelhantemente foi assim com a filosofia efetivamente fundamentada na religião, embora crítica em vários momentos como mencionado, sendo, porém, no período medieval tratada como serva da Teologia - philosophia ancilla theologiae (ABBAGNANO, 2012, p. 1003). Possivelmente por isso, não se falava em uma Filosofia da Religião como área específica de conhecimento.

Com a autonomização das áreas do conhecimento e o advento da ideia de indivíduo, fenômenos próprios da modernidade, a religião passa a ser vista também como uma área particular da cultura humana. Processo que acelera no século XIX com as especializações das ciências. Embora deve-se observar que o processo do conceito de indivíduo na religião é gradual até chegar na forma mais subjetiva, na qual a religião é vista como uma questão de liberdade, de escolha individual. Deve-se também observar que não se trata de um desenvolvimento linear e uniforme em todos os lugares e épocas. No mundo ocidental, de certa forma, a reforma protestante cooperou para a ideia de liberdade religiosa, tendo em vista a possibilidade dada a cada indivíduo de poder ler a Bíblia e dar conta de si mesmo diretamente a Deus, ao invés de ficar obrigado às interpretações doutrinárias do magistério da Igreja de Roma e à sua hierarquia clerical. A liberdade religiosa será disseminada e defendida em países que se tornaram hegemonicamente protestantes como a Inglaterra e a Alemanha. O filósofo inglês John Locke a defenderá em sua Carta acerca da tolerância (1689). As constantes guerras entre ciência e religião, na disputa de mentes e corações, 
também acirraram ainda mais a separação entre uma e outra área da cultura humana. Com o ápice do positivismo científico no século XIX e início do século XX, a religião tornou-se motivo de desconfiança por parte de cientistas. Alguns religiosos também, por sua vez, reagiriam se defendendo contra as ciências, como os fundamentalistas que surgem nesse mesmo período ${ }^{2}$. O mundo conhecia assim progressivamente, o que parecia definitivamente ser o "Desencantamento do mundo", conforme a tese de Max Weber, e o processo inevitável da secularização.

É fato que a religião não deixou de existir e de fazer parte da vida humana no século XX e continua muito presente no século XXI. Embora continue a fundamentar boa parte da conduta e das instituições humanas, ela não possui mais hegemonia social e disputa agora seu espaço com outras áreas da cultura e das várias instituições modernas. Portanto, a religião se autonomizou. E assim tornou possível falar-se de uma Filosofia da Religião como subárea específica da Filosofia. A Filosofia da Religião nos moldes iluministas, cuja obra icônica é o livro de Kant que, apesar de sua originalidade em inaugurar uma reflexão que permitisse pensar a religião de forma racional, sem necessariamente sujeitar tal pensamento à Revelação, estava ainda assim, fundamentada na teologia cristã. Além disso, toda a sua argumentação é restrita a um racionalismo rígido. As críticas de Feuerbach, Marx, Nietzsche e Freud foram importantes para captar a origem humana, psicológica e social das quais surge a religião e a tornam "necessária”. Não obstante a importância e assertividade dessas críticas, mostraram-se, entretanto, limitadas por terem errado seu prognóstico sobre o fim da religião.

Com o advento das pesquisas antropológicas e linguísticas, tornou-se possível o surgimento da Ciência da Religião, assim batizada por Max Müller no século XIX. No século XX, em uma outra etapa acerca da reflexão sobre a religião surgem a abordagens como as de Rudolf Otto e de Mircea Eliade, que a seu modo cada um deles conceberam acerca da essencialidade da religião como sendo a do Sagrado, o que

2 Os famosos escritos da coletânea "The Fundamentals" (1909) são um conjunto de textos notórios por essa intensa defesa de doutrinas cristãs na visão protestante norte-americana contra as formas de pensamento positivo científico que, supostamente, as colocavam em perigo. Aqui no Brasil publicado como TORREY, R.A. (Edit.). Os Fundamentos: A famosa coletânea de textos das verdades bíblicas fundamentais. Tradução Cláudio J.A. Rodrigues. São Paulo: Hagnos, 2005. 
muito contribuiu para uma consideração acerca da especificidade do fenômeno. Mircea Eliade, principalmente, o faz por meio da pesquisa empírica e histórica da religião. Por motivo de espaço e tempo, não se aprofundou aqui estas abordagens, mas julga-se serem pontos de inflexão para uma Filosofia da Religião em maior consonância com a Ciência da Religião, e que de certa forma, se esforçam para se afastar das perspectivas de filosofias religiosas.

Neste ensaio, propõe-se uma filosofia da religião que não seja uma filosofia religiosa e nem teologia, tampouco uma apologética da religião e da crença. Por outro lado, também não é desejável reduzir em uma crítica que tenha por finalidade a eliminação da religião no mundo por meio do esclarecimento, do positivismo e das ciências, sob o preço da substituição de formas não racionais por outras, ditas mais racionais. A proposta que aqui se apresenta de uma filosofia da religião, procura englobar tanto seu aspecto crítico, quanto seu aspecto de fundamentação, porém sem cair em um desses extremos. Trata-se de uma abordagem que esteja em consonância com a Ciência da Religião. Uma filosofia da religião que seja criticamente fundamentada ou fundamentalmente crítica.

\section{Problema: filosofias da religião apologéticas ou religiosas}

A razão pela qual o autor deste artigo propõe-se esta tarefa, é verificar que, em meio aos estudos filosóficos de religião, ainda se depara com filosofias que são mais apologéticas do que "filosóficas" propriamente ditas e que, não obstante, ao se apresentarem como filosofia, acabam por demonstrarem-se muito mais como defesas de uma religião específica, em especial o cristianismo ${ }^{3}$. Não se ignora que a filosofia tenha tido, durante séculos, uma relação muito estreita e até

Exemplifica-se algumas obras que, não obstante serem dedicadas ao tema da Filosofia da Religião, dedicam-se mais a defesa da ideia de Deus em termos e conceitos historicamente mais ligados ou forjados no seio do cristianismo, a questão dos argumentos a favor de sua existência, aos dados da revelação etc. Ou seja, apresentam, a nosso ver, um tom mais apologético. Nota-se, por outro lado, uma certa reserva desses autores com relação aos filósofos mais críticos, ao comentá-los os reduzem à pecha de "ateus": ZILLES, Urbano. Filosofia da Religião. São Paulo: Paulus, 1991; MORELAND, J.P. \& CRAIG, Willian Lane. Filosofia e cosmovisão cristã. Tradução Emirson Justino, Hander Heim, Lena Aranha, Rogério Portella e Sueli da Silva Saraiva. São Paulo: Vida Nova, 2005. 
subordinada à religião cristã, a ponto de boa parte da filosofia medieval ser basicamente filosofia cristã, e que tal filosofia não tenha a sua importância na história do pensamento. Também não se deve ignorar que uma filosofia religiosa tenha o seu lugar e possa contribuir de alguma forma, por exemplo, articulando mesmo que a defesa de determinada religião com as questões mais amplas da sociedade e em prol destas últimas. E por último que filosofias religiosas não possam fornecer reflexões de temas que podem entrar em um profícuo debate com a filosofia em geral. Tudo isso não pode e não deve ser ignorado no pensamento filosófico. Porém, uma filosofia estritamente religiosa será de pouca valia ao público mais amplo da sociedade ou ao desenvolvimento epistemológico da Ciência da Religião, se reduzir-se apenas a defesa de uma fé ou confissão religiosa. Neste caso, pode até ser útil aos membros daquela confissão, não obstante privá-los de um diálogo mais profícuo com um debate mais amplo com as ciências como um todo, especialmente no trato com o sentido da religiosidade de maneira geral. Assim, reconhece-se que existe espaço e possibilidades para uma filosofia religiosa, mas entende-se como limitado. Também, por outro lado, não é desejável cair no outro extremo de uma filosofia que se coloque de forma militante contra a religião ou a religiosidade, algo como uma filosofia tipicamente ateísta, posto que isto também seria a proposta de um outro tipo de religiosidade em espécie ao reverso. Sem negar que haja possibilidade para filosofias religiosas e ateias, propõe-se uma "terceira via", que caminha no espírito de um pensamento filosófico mais alinhado à Ciência da Religião.

\section{Hipótese: religião como linguagem}

Pensar uma filosofia da religião que considere o fenômeno religioso de forma ampla, abarcando não a defesa de uma religião específica. Aliás, sem abarcar a defesa de qualquer religião, mas considerando-a como intrinsecamente cultural, sem deixar de olhar sua especificidade frente às demais produções culturais da humanidade, como o direito, a economia, a arte etc. Entende-se que uma proposta deste tipo respeita o objeto de estudo "religião", sem, no entanto, fazer julgamento de valores sobre um tipo específico. 
As abordagens hermenêuticas e fenomenológicas da religião caminharam muito nesta direção, Paul Tillich com o conceito de relação, Rudolf Otto com o conceito de sagrado, Mircea Eliade como o de hierofania, Paul Ricoeur em seus estudos sobre hermenêutica, entre outros. São abordagens que poderiam estar articuladas a essa proposta. Entretanto, por questões de corte metodológico, optou-se por uma outra abordagem. Enfatiza-se aqui a abordagem da religião como linguagem, como uma possível solução para uma filosofia não religiosa da religião. É fato que não há nisso nenhuma novidade. Antes, trata-se de uma reflexão a partir do que já vem sendo produzido no âmbito da Filosofia da Religião, e mesmo, na própria Ciência da Religião. Até porque já há uma área de pesquisa chamada "Linguagens da Religião"4. Procura-se aqui poder contribuir um pouco mais com este debate, seja retomando algumas ideias ou abrindo para novas abordagens.

Pensa-se em um modelo filosófico que seja mais adequado ao tratamento científico das religiões e que se afaste de uma apresentação apologética da religião. Que não seja nem teologia e nem filosofia religiosa. Mas que se atenha mais às características do fenômeno religioso como tal. Portanto, mais descritivo e menos avaliativo. Entende-se que uma abordagem de Filosofia da Religião que se aproxima mais dessa tratativa é a que compreende a religião como linguagem. Se apresentaria como metateoria da Religião ou metateoria científico religiosa. Conforme Hock

A Filosofia da Religião como disciplina fundamental, como metateoria é uma forma de reflexão que se impõe ainda antes da Crítica à Religião e da Fundamentação da Religião. Nessa função, ela procura uma reflexão não normativa e se abstém de todas as tentativas de fundamentar ou defender uma determinada posição religiosa. Sua tarefa consiste prioritariamente em discutir a questão sobre o que distingue o religioso do não religioso - portanto contribuir para o esclarecimento do conceito de religião (2010, p. 201).

Nesta abordagem, a Filosofia da Religião não se sobrepõe a partir de uma teologia, tampouco de mera crítica a uma abordagem teológica. Não se trata de impor ou criticar a religião por uma visão de uma

\footnotetext{
Ou outras variantes.
} 
religião. Mas de uma consideração pelo fenômeno religioso de forma a contribuir na conceituação do que é o religioso ou o que é a religião. Reconhecendo-o enquanto existente e específico na sociedade e na cultura humana e, portanto, digno de uma tratativa científica enquanto tal. Que a fundamente, mas também critique as abordagens apologéticas. Trata-se assim, de tentar responder à pergunta "O que é religião?", obviamente não com o objetivo de exaurir a questão. Neste sentido, pode-se afirmar que religião é linguagem.

Pode parecer redutor ver a religião como linguagem. E de fato, não se está inferindo que a religião é somente linguagem. Mas que a função da linguagem exerce sobre o fenômeno o papel estruturante, expressivo, performativo e comunicativo. Assim, a religião como linguagem se apresenta como possível de ser analisada cientificamente. Contudo, não se trata de verificar se as afirmações das religiões são verdadeiras ou falsas, mas sim de capturar o fato linguístico da religião e a partir deste poder analisar o fenômeno religioso se apresentando como tal, isto é, como linguagem.

\section{Da filosofia da linguagem aos jogos de linguagem}

A história da filosofia teve um momento de inflexão bastante significativo a partir do fim do século XIX com a filosofia analítica que dá origem à filosofia da linguagem do século XX. Conforme Marcondes, "A filosofia analítica considera que o tratamento e a solução de problemas filosóficos devem se dar por meio da análise lógica da linguagem (1997, p. 261)." A análise lógica consiste em reduzir a linguagem a afirmações de juízo, isto é, proposições. Na perspectiva geral da filosofia analítica, o papel do filósofo é analisar estes juízos e verificar sua forma lógica, sua estrutura e a relação dos termos entre si, de forma a considerar sua validade ou falsidade. Marcondes explica que a filosofia analítica buscava uma correspondência entre a realidade e a linguagem. Uma linguagem só será válida se houver correspondência com a realidade. Portanto não se trata da linguagem comum dos idiomas, mas de estabelecer uma linguagem científica. Fato é que os filósofos analíticos até buscaram criar uma linguagem simbólica e matemática. Alguns dos principais filósofos analíticos foram Gottlob Frege, Bertrand Russel e Ludwig Wittgenstein (o do Tractatus Logico-Philosophicus de 1922). 
Surge assim o famoso Círculo de Viena com Moritz Schlick (18821936), Otto Neurath (1882-1945) e Rudolph Carnap (1891-1970) no início do século XX que deu origem ao chamado Positivismo Lógico. Segundo Marcondes

Assim como os filósofos analíticos, os pensadores do Círculo de Viena combatiam o pensamento metafísico especulativo originário do idealismo alemão. Seu propósito era fundamentar na lógica uma ciência empírico formal da natureza e empregar métodos lógicos e rigor científico no tratamento das questões de ética, filosofia da psicologia e ciências sociais, sobretudo economia e sociologia (1997, p. 262).

Nota-se que esses pensadores que destacaram o papel da linguagem para determinação da realidade estavam muito vinculados a um tipo de ciência positivista. Porém o seu papel de dar destaque à linguagem foi importante para a concepção de uma filosofia e de uma ciência que pudesse conceber a linguagem como estruturante lógica e que permitiria, assim, uma possibilidade de análise científica de várias questões da humanidade, por meio de uma análise lógico-linguística. A professora de filosofia Inês Lacerda Araújo, especialista em filosofia da linguagem, diz que "Com a virada linguística (linguistic turn), o pensamento ocidental volta-se para o problema da linguagem, o que provocou transformações rápidas e importantes na linguística e na filosofia da linguagem" (ARAÚJO, 2004, p. 11). Portanto, o pensamento filosófico pela linguagem ganha outro contorno e importância que modifica a análise do homem e da cultura, não mais por um viés metafísico ou idealista, mas através da análise do discurso e da linguagem como, inclusive, estruturante do pensar e da própria produção cultural. Araújo afirma ainda nesse sentido que

A linguagem não é mais considerada como simples instrumento para o pensamento representar as coisas, e sim estrutura articulada, independente de um sujeito ou de uma vontade individual e subjetiva, não mais submetida à função exclusiva da nomeação ou designação, o que quer dizer que o signo não se limita a estabelecer uma relação direta com a coisa nomeada. Temos assim, no lugar de uma análise das representações, a análise da linguagem, cujas expressões gramaticais são públicas (2004, p. 12). 
Sendo a linguagem estruturante do sujeito, de sua forma de ser e pensar no mundo, a linguagem será fundamental no chamado estruturalismo. Conforme Araújo "o estruturalismo mostra que sem linguagem não há cultura, nem pensamento, nem personalidade". O estruturalismo foi importante movimento, especialmente da França nos anos 1960 que parte da linguística de Ferdinand de Saussure (1857-1913) (WOODWARD, 2016, p. 109). E cujos expoentes a aplicam às diversas áreas das humanidades: antropologia, filosofia, teoria literária, direito e inclusive nas ciências das religiões (FILORAMO \& PRANDI, 1999, p. 215).

É, entretanto, a "filosofia da linguagem ordinária" que surge nos anos 40 a 60 do século XX que permitirá pensar o lado mais pragmático da linguagem (MARCONDES, 1997, p. 263). A chamada "virada pragmática" da linguagem. O principal representante dessa corrente é o chamado Segundo Wittgenstein com sua obra Investigações Filosóficas, na qual se encontra a questão dos jogos de linguagem. Houve um grande avanço para a filosofia da linguagem com esta inflexão. Pois no Positivismo Lógico, conforme Carvalho, que aplica com sucesso a filosofia da linguagem ao Direito, "Ao conceber uma linguagem ideal para as ciências, construíram um paradigma linguístico empobrecido no plano pragmático" $(2018$, p. 28). A diferença na proposta da linguagem ordinária com relação ao Círculo de Viena, é que os novos filósofos da linguagem, com a nova abordagem, se atêm ao uso comum, ao contexto e à experiência concreta em que se dá a linguagem e não apenas às fórmulas e estruturas lógicas. Não se trata de uma abstração matemática da linguagem retirando-a do contexto real dos fenômenos sociais, mas de entender a própria dinâmica linguística na experiência real, vivida e concreta dos falantes. Conforme Wittgenstein:

O termo "jogo de linguagem" deve aqui salientar que o falar da linguagem é uma parte de uma atividade ou de uma forma de vida.

Imagine a multiplicidade dos jogos de linguagem por meio destes exemplos e outros:

Comandar, e agir segundo comandos -

Descrever um objeto conforme a aparência ou conforme medidas Produzir um objeto segundo uma descrição (desenho) Relatar um acontecimento -

Expor uma hipótese e prová-la - 
Apresentar os resultados de um experimento por meio de tabelas e diagramas -

Inventar uma história; ler -

Representar teatro -

Cantar uma cantiga de roda -

Fazer uma anedota; contar -

Resolver um exemplo de cálculo aplicado -

Traduzir de uma língua para outra -

Pedir, agradecer, maldizer, saudar, orar.

- É interessante comparar a multiplicidade das ferramentas da linguagem e seus modos de emprego, a multiplicidade das espécies de palavras e frases com aquilo que os lógicos disseram sobre a estrutura da linguagem

(é também o autor do Tractatus Logico-philosophicus) (1999, pp. 35-36).

Com o conceito de "jogo de linguagem", Wittgenstein trouxe à filosofia analítica da linguagem à dimensão pragmática do uso e do contexto em que se dão as dinâmicas variadas, múltiplas da linguagem nas várias situações humanas, diferenciando da abordagem positivista reducionista da linguagem do Primeiro Wittgenstein e do Positivismo Lógico. Cada um dos usos de linguagem que o filósofo descreveu como exemplo em seu texto, apontam para regras específicas próprias da dinâmica linguística de cada atividade. Portanto, não é possível uma compreensão uniforme de fenômenos humanos e sociais, sem entender como cada um desses fenômenos singulares se comunicam internamente. Com isso, abre-se a possibilidade de entender os sentidos dos fenômenos, mas que só poderão ser inferidos a partir da compreensão de suas próprias regras internas. Haverá tantas linguagens quanto houver usos da linguagem que estiverem em ação nas mais diversas situações. Ainda que as mesmas palavras, gestos ou imagens possam ser usadas, se forem usadas por grupos diferentes em diferentes contextos e combinações, lida-se com um outro jogo de linguagem, cuja regra será necessária decifrar com a análise do fenômeno específico que se apresenta.

\section{Da(s) religião(ões) como um(alguns) jogo(s) de linguagem}

Mas como uma ciência pode ser produzida tendo em vista tamanha variedade? Deve-se ter em mente que a própria linguagem científica também é um jogo de linguagem. E possui suas próprias regras. Ao fazer uma Ciência da religião, o cientista estará munido das regras do jogo 
científico, ou poderíamos dizer, método científico. Quando um cientista da religião analisa uma religião, deve analisar o fenômeno específico e singular, procurando entender a linguagem subjacente do objeto de sua pesquisa. Porém, ao elaborar a descrição da religião, não utilizará a linguagem religiosa como estrutura do pensamento científico. Mas uma linguagem de sobrenível ${ }^{5}$, a linguagem da Ciência da Religião, que é de caráter descritivo. Ao passo que a própria linguagem religiosa, não se propõe, necessariamente, a ser meramente descritiva e nem científica, mas está dentro de seu próprio "jogo". Assim tem-se na composição de um texto de Ciência da Religião, uma intertextualidade presente entre a linguagem da religião ou religiosa e a linguagem da pesquisa científica, com sobreposição desta segunda, porém sem descaracterizar a primeira. A questão intrinsecamente filosófica que aí se impõe é analisar qual seria a característica essencial do "jogo" de linguagem religioso, isto é, se é possível identificar um princípio geral que possa ser observado em todos os fenômenos denominados como "religiosos". Autores como Mircea Eliade com o conceito de hierofania e Rudolf Otto com o conceito de sagrado, fizeram avanços significativos nesse sentido, reservando a especificidade da religião frente aos outros fenômenos culturais. Ou seja, enquanto a linguagem religiosa busca expressar, comunicar, viver etc. o sentido sagrado ou hierofânico ${ }^{6}$, a Ciência da religião tentaria descrever de que maneira a linguagem de uma específica religião objeto de estudo expressa, comunica e vive esse sagrado, por meio da linguagem ou do jogo de linguagem que coloca em operação.

Nogueira (2016, pp. 240-261) em um de seus inúmeros artigos, apresenta uma proposta teórica para analisar a relação entre religião e linguagem. No qual diz que, embora pudesse se afirmar que a linguagem estrutura a religião, prefere "subir um nível em nossa determinação linguística da religião ao dizer que qualquer experiência religiosa só pode ser tornada social por meio das convenções linguísticas (p. 243)." Para evitar reduzir a religião em linguagem, caminha pela abordagem

5 Deve-se esta percepção e esta expressão aos estudos do Constructivismo LógicoSemântico que aplica a filosofia da linguagem ao estudo científico do direito. Para maior aprofundamento veja, por exemplo: CARVALHO, Aurora Tomazini de. Curso de Teoria Geral do Direito: O Constructivismo Lógico-Semântico. 5. ed. São Paulo: Noeses, 2016.

6 Expressão conceitual sobre a especificidade do fenômeno religioso utilizada por Mircea Eliade. 
de Iuri Lotman, o qual entende que "a religião é um sistema secundário de linguagem, com poder de dar forma ao mundo" (p. 245). Lotman, comentado por Nogueira, ensina que no mundo existem as línguas naturais faladas no dia a dia para nomear as coisas e existem as linguagens de segundo nível da cultura, como a jurídica, a econômica, as das ciências, as religiosas etc. (p. 244).

Nos dois níveis a língua não tem um papel de reproduzir o real, antes ela o molda, tornando-o possível. Retomando a analogia: da mesma forma que a língua fornece a uma criança, no aprendizado de sua língua materna, modelos para apreender o mundo em que vive, seus valores etc., de forma similar a cultura, imitando a linguagem, nos dá modelos de mundo em suas linguagens específicas: a jurídica, a artística, a política, e a religiosa, entre outras. Nesse sistema lotmaniano, o dualismo entre linguagem (forma de expressão) e religião (conteúdos) se dissolve, uma vez que a própria religião se porta como um sistema secundário de linguagem, com poder de dar forma ao mundo (p.245).

Deve-se ter atenção em não confundir o que diz Nogueira com o que foi dito mais acima sobre o sobrenível da linguagem da Ciência da Religião. A linguagem da religião, como segundo nível de linguagem (Lotman), não tem a finalidade de meramente nomear, como a linguagem natural e nem a de descrever como a linguagem da Ciência da Religião e demais ciências. A linguagem religiosa é uma linguagem que visa dar sentido, "dar forma ao mundo", daquele que dela passe a se utilizar. A religião, entendida assim como esse tipo de linguagem, pode ser percebida como "sistema de ordenamento do mundo", pelo menos para o adepto da religião que passa a repetir gestos, palavras e utilizar-se de imagens e narrativas próprias de sua religião na sua interpretação do mundo e da vida (p. 251).

O que é ainda importante destacar do artigo de Nogueira, para as finalidades do presente artigo, é que os sistemas de linguagens das religiões não se reduzem a textos escritos ou mesmo à oralidade. Mas tais sistemas contemplam: gesto, imagem-metáfora e narrativa, às quais correspondem sistemas semióticos elementares. Ao gesto corresponde o rito, à imagem-metáfora corresponde o ícone e à poesia e à narrativa corresponde o mito (p. 251). A religião se apresenta assim como linguagem por meio desses sistemas semióticos que inclusive se relacionam entre si. A performance 
religiosa ocorre produzindo e reproduzindo seus conteúdos, experiências, discursos etc. específicos nestes sistemas semióticos.

\section{Conclusão}

Religião como linguagem torna-se apreensível ao estudo científico que se incumbirá de analisar a linguagem religiosa de determinada religião para compreendê-la: gestos, imagens e narrativas. Uma filosofia da religião precisa considerar o aspecto linguageiro da religião. Daí abordagens filosóficas como a hermenêutica, deverem ser mantidas no horizonte da pesquisa sobre religião, articuladas com a filosofia da linguagem, o estruturalismo e o pós-estruturalismo que mantiveram em suas análises a reflexão sobre o discurso.

Dizer que religião é linguagem não é reduzir a religião à escrita ou mesmo à oralidade. Linguagem aqui deve ser entendida em sentido amplo e conjunto que articula as formas de comunicação, expressão, estruturação e performance. A presente proposta vai além da abordagem de Max Müller em sua análise de línguas comparadas em seus estudos de religião7. Mesmo o gesto do "silêncio" dentro de uma religião, está ligado à linguagem que a estrutura ou a produz. De alguma forma foi estabelecido o momento ou exercício do silêncio. A teoria dos jogos de linguagem de Wittgenstein nos ajuda a entender que o processo de linguagem se dá por meio de regras internas próprias. Há um jogo de linguagem próprio de cada manifestação religiosa. Não dizemos nem de cada religião, já que a maneira como os adeptos de cada religião performam, pode mudar no tempo e no espaço. Adicionalmente, outras teorias, como a dos "atos de fala" de J.L. Austin, por exemplo, podem contribuir para o entendimento da performatividade da linguagem própria a um ambiente religioso específico (MARCONDES, 1997, p. 264). Essa preocupação com o dinamismo e a variedade da performance religiosa é necessária, pois do contrário, seríamos tentados, ao considerar religião como linguagem, simplesmente por suas produções escritas como os textos sagrados e as interpretações oficiais. Ocorre que frequentemente adeptos de religiões agem contra o próprio discurso oficial. Portanto, considerar religião como linguagem é algo que não desconsidera o lado

Ver FILORAMO, G. \& PRANDI, C. Op. Citado, pp. 227-234. 
pragmático, cujo acesso ao cientista da religião deve se dar por uma análise empírica do jogo de linguagem presente. Isso move o cientista da religião que atua com a pesquisa empírica a articular constantemente prática religiosa com os escritos oficiais e com análises dos contextos cultural, social, econômico e político do momento (na conjuntura) em que se dá a prática. Fazendo assim, o cientista da religião municiado de uma filosofia da religião como linguagem, pode compreender qual o jogo de linguagem está sendo "jogado" por aquele grupo específico e naquele momento (conjuntura).

Com uma perspectiva deste gênero, a Filosofia da religião deixa de ser meramente crítica e meramente apologética de uma religião. Todas as religiões com suas linguagens possuem sentidos, o que não quer dizer que todas as afirmações que fazem são verdadeiras ou falsas. Pesquisar religião como linguagem é entender que há códigos e sentidos próprios da religião, de cada religião e às vezes, de cada manifestação religiosa. Um tipo de linguagem que não é o mesmo da filosofia e da ciência. Haverá tantas linguagens da religião, quantas manifestações ou religiões existirem. Mas para que a Ciência da Religião possa exercer o método científico e se constituir em discurso cognitivo e científico do fenômeno religioso, precisa estabelecer uma linguagem de sobrenível, que não pode ser uma linguagem religiosa, mas científica. Uma linguagem cognitiva e descritiva.

Portanto, entende-se que uma filosofia da religião assim poderá ser fundamentalmente crítica, a medida em que verifica os limites de filosofias da religião que se apresentam como filosofias religiosas, como defesas de alguma religião específica. E poderá ser criticamente fundamentada, a medida em que considera todo o aparato crítico-filosófico da filosofia para ajudar a fundamentar o conceito de religião, de forma a torná-lo possível a um estudo científico e a manter no horizonte a religião como objeto partícipe da cultura humana.

Como último approach, entende-se que apesar do principal problema enfrentado pela Ciência da Religião frente aos embates positivistas ser o fato de que os dados das afirmações das crenças religiosas não serem cientificamente verificáveis, não quer dizer que não sejam válidos ou que não tenham sentido. Não é necessário agir como os filósofos do Círculo de Viena, cuja "abordagem mais radical aos problemas do 
sentido dos termos religiosos seria a de simplesmente rejeitá-los como sem sentido (WILKINSON \& CAMPBELL, 2014, p. 286)." O filósofo e o cientista da religião poderão partir das seguintes hipóteses: 1) Os dados das afirmações religiosas fazem sentido para o religioso; 2) os dados das afirmações religiosas são simbólicos; 3) embora a referência para o religioso é o sobrenatural, ele o faz a partir de uma vivência concreta e 4) o religioso vive a experiência religiosa e a ela se refere por meio da linguagem. Conclusão: cabe ao filósofo e ao cientista da religião analisar essa linguagem.

Recapitulando: há a linguagem natural e ordinária, há a linguagem cultural que dá sentido e forma ao mundo (a religiosa, por exemplo) e há a linguagem do cientista que procura descrever os fenômenos. $\mathrm{Na}$ intertextualidade produzimos relações, articulações e sobreposições entre essas linguagens, porém, sem confundi-las, especialmente se estivermos fazendo ciência.

\section{Referências Bibliográficas:}

ABBAGnANO, N. Dicionário de Filosofia. Tradução Alfredo Bosi e Ivone Castilho Benedetti. 6. ed. São Paulo: WMF Martins Fontes, 2012, p. 1003.

CARVAlHO, A. T. Curso de Teoria Geral do Direito: O Constructivismo Lógico-Semântico. 5. ed. São Paulo: Noeses, 2016.

CARVALHO, P. B. Direito Tributário, linguagem e método. 7. ed. rev. São Paulo: Noeses, 2018, p. 28.

FILORAMO, G. \& PRANDI, C. As Ciências das Religiões. Tradução José Maria de Almeida. São Paulo: Paulus, 1999, p. 215

HOCK, K. Introdução à Ciência da Religião. Tradução Monika Otterman. São Paulo: Loyola, 2010, p. 201.

MARCONDES, D. Iniciação à História da Filosofia: Dos pré-socráticos a Wittgenstein. Rio de Janeiro: Jorge Zahar, 1997, p. 261.

NOGUEIRA, P. A. S. Religião e linguagem: proposta de articulação de um campo complexo. Horizonte, Belo Horizonte, v. 14., n. 42, pp. 240-261, abr./ jun. 2016.

WILKINSON, M. B. \& CAMPBELL, H. N. Filosofia da Religião: Uma introdução. Tradução Anoar Jarbas Provenzi. São Paulo: Paulinas, 2014.

WITTGENSTEIN, L. Investigações Filosóficas. Tradução José Carlos Bruni. São Paulo: Nova Cultural, 1999 (Coleção "Os Pensadores").

WOODWARD, A. Nietzscheanismo. Tradução Diego Kosbiau Trevisan. Petrópolis, RJ: Vozes, 2016, p. 109.

Submetido em: 22-8-2021

Aceito em: 3-9-2021 